Reply

\title{
Reply to Nayak, P.K. Comment on "Samulewski et al. Magnetite Synthesis in the Presence of Cyanide or Thiocyanate under Prebiotic Chemistry Conditions. Life 2020, 10, 34"
}

\author{
Rafael Block Samulewski ${ }^{1}$, Flávio F. Ivashita ${ }^{2}$, Andrea Paesano, $\mathrm{Jr}^{2}{ }^{2}$ and Dimas Augusto Morozin Zaia ${ }^{1, *(\mathbb{D})}$ \\ 1 Departamento de Química, Universidade Estadual de Londrina, Londrina CEP 86057-970, PR, Brazil; \\ blockeness@gmail.com \\ 2 Departamento de Física-CCE, Universidade Estadual de Maringá, Maringá 87020-900, PR, Brazil; \\ fivashita@gmail.com (F.F.I.); paesano@wnet.com.br (A.P.J.) \\ * Correspondence: damzaia@uel.br
}

check for updates

Citation: Samulewski, R.B.; Ivashita, F.F.; Paesano, A., Jr.; Zaia, D.A.M. Reply to Nayak, P.K. Comment on “Samulewski et al. Magnetite Synthesis in the Presence of Cyanide or Thiocyanate under Prebiotic Chemistry Conditions. Life 2020, 10, 34". Life 2021, 11, 1416. https:// doi.org/10.3390/life11121416

Academic Editor:

César Menor-Salván

Received: 17 September 2021

Accepted: 2 December 2021

Published: 17 December 2021

Publisher's Note: MDPI stays neutral with regard to jurisdictional claims in published maps and institutional affiliations.

Copyright: (c) 2021 by the authors. Licensee MDPI, Basel, Switzerland. This article is an open access article distributed under the terms and conditions of the Creative Commons Attribution (CC BY) license (https:/ / creativecommons.org/licenses/by/ $4.0 /)$.
We have considered the criticisms raised by Pranaba K. Nayak [1] regarding the Mössbauer analysis presented in our paper "Magnetite Synthesis in the Presence of Cyanide or Thiocyanate under Prebiotic Chemistry Conditions" [2] and, in our opinion, the issues addressed make sense. However, we do not believe that any of them implied mistakes regarding the final conclusions of the paper.

First of all, we recognize that the Mössbauer spectra of the MG4P, MG4CN, and MG4SC samples should be fitted considering three sextets and a doublet (thus performing 20 lines and not 18, as pointed out by Nayak). In this sense, we believe that the complainant is correct. Therefore, new fits were performed-for the spectra of samples containing goethite-and the spectra are provided in Figure 1, with hyperfine parameters presented in Table 1 (sextet $A+$ sextet $B$ for magnetite, sextet $C$ or a hyperfine field distribution $/ B_{h f}$ Dist. for goethite, and a doublet for ferrihydrite). The uncertainties of the fitted parameters, subspectral areas, and linewidths have been included in the new table. It can be observed that goethite amounts, if any, are not small at all, justifying the point raised by the questioner. It is also worth noting the (large) linewidths found for the goethite discrete sextets, indicating some degree of hyperfine field distribution.

Table 1. Mössbauer hyperfine parameters of all samples and iron mineral correspondence.

\begin{tabular}{|c|c|c|c|c|c|c|c|}
\hline Sample & Mineral & $\begin{array}{c}\text { Sub } \\
\text { Spectrum }\end{array}$ & $\begin{array}{c}\Gamma / \\
\mathrm{mm} \mathrm{s}^{-1}\end{array}$ & $\begin{array}{c}\text { IS/ } \\
\mathrm{mm} \mathrm{s}^{-1}\end{array}$ & $\begin{array}{c}\mathrm{QS} / \\
\mathrm{mm} \mathrm{s}^{-1}\end{array}$ & $\begin{array}{c}\text { Bhf/ } \\
\text { T }\end{array}$ & $\begin{array}{l}\mathrm{A} / \\
\%\end{array}$ \\
\hline \multirow{2}{*}{ MGP } & \multirow{2}{*}{ Magnetite } & Sext A & 0.52 & 0.34 & -0.08 & 48.5 & 52.2 \\
\hline & & Sext B & 0.46 & 0.65 & -0.01 & 45.1 & 47.8 \\
\hline \multirow{4}{*}{ MGP4 } & \multirow{2}{*}{ Magnetite } & Sext A & 0.53 & 0.33 & 0.00 & 47.9 & 32.0 \\
\hline & & Sext B & 0.64 & 0.62 & -0.12 & 44.5 & 17.8 \\
\hline & \multirow{2}{*}{$\begin{array}{c}\text { Ferrihydrite } \\
\text { Goethite }\end{array}$} & Doublet & 0.57 & 0.37 & 0.78 & - & 31.0 \\
\hline & & Sext C & 1.99 & 0.35 * & $0.07 *$ & 39.0 * & 19.2 \\
\hline \multirow{4}{*}{ MGCN4 } & \multirow{2}{*}{ Magnetite } & Sext A & 0.50 & 0.33 & -0.02 & 49.2 & 30.0 \\
\hline & & Sext B & 0.67 & 0.55 & 0.08 & 45.3 & 12.8 \\
\hline & \multirow{2}{*}{$\begin{array}{l}\text { Ferrihydrite } \\
\text { Goethite }\end{array}$} & Doublet & 0.52 & 0.36 & 0.69 & - & 42.8 \\
\hline & & Sext C & $1.60 *$ & 0.36 & 0.07 & 39.0 & 14.4 \\
\hline \multirow{4}{*}{ MGSCN4 } & \multirow{2}{*}{ Magnetite } & Sext A & 0.50 & 0.33 & -0.02 & 49.2 & 30.2 \\
\hline & & Sext B & 0.70 & 0.51 & 0.07 & 45.2 & 13.4 \\
\hline & \multirow{2}{*}{$\begin{array}{c}\text { Ferrihydrite } \\
\text { Goethite }\end{array}$} & Doublet & 0.52 & 0.36 & 0.69 & - & 42.9 \\
\hline & & Sext C & $1.60 *$ & 0.35 * & 0.08 & 38.6 & 13.5 \\
\hline
\end{tabular}


Table 1. Cont.

\begin{tabular}{|c|c|c|c|c|c|c|c|}
\hline Sample & Mineral & $\begin{array}{c}\text { Sub } \\
\text { Spectrum }\end{array}$ & $\begin{array}{c}\Gamma / \\
\mathrm{mm} \mathrm{s}^{-1}\end{array}$ & $\begin{array}{c}\text { IS/ } \\
\mathrm{mm} \mathrm{s}^{-1}\end{array}$ & $\begin{array}{c}\mathrm{QS} / \\
\mathrm{mm} \mathrm{s}^{-1}\end{array}$ & $\begin{array}{c}\text { Bhf/ } \\
\text { T }\end{array}$ & $\begin{array}{l}\mathrm{A} / \\
\%\end{array}$ \\
\hline \multirow{2}{*}{ MGCN } & \multirow{2}{*}{ Magnetite } & Sext A & 0.52 & 0.33 & -0.08 & 48.5 & 59.7 \\
\hline & & Sext B & 0.48 & 0.65 & -0.09 & 45.4 & 40.3 \\
\hline \multirow{4}{*}{ MGSCN } & \multirow{2}{*}{ Magnetite } & Sext A & 0.47 & 0.32 & -0.04 & 48.5 & 23.7 \\
\hline & & Sext B & 1.09 & 0.47 & 0.02 & 44.2 & 30.5 \\
\hline & Ferrihydrite & Doublet & 0.51 & 0.37 & 0.63 & - & 7.3 \\
\hline & Goethite & Dist. & 0.30 * & 0.39 & 0.00 * & 25.1 & 38.5 \\
\hline
\end{tabular}

* Fixed parameters. ( $\Gamma$-Line width; IS-Isomer shift; QS-Quadrupole splitting; Bhf-Magnetic hyperfine field; A-Subspectrum area).
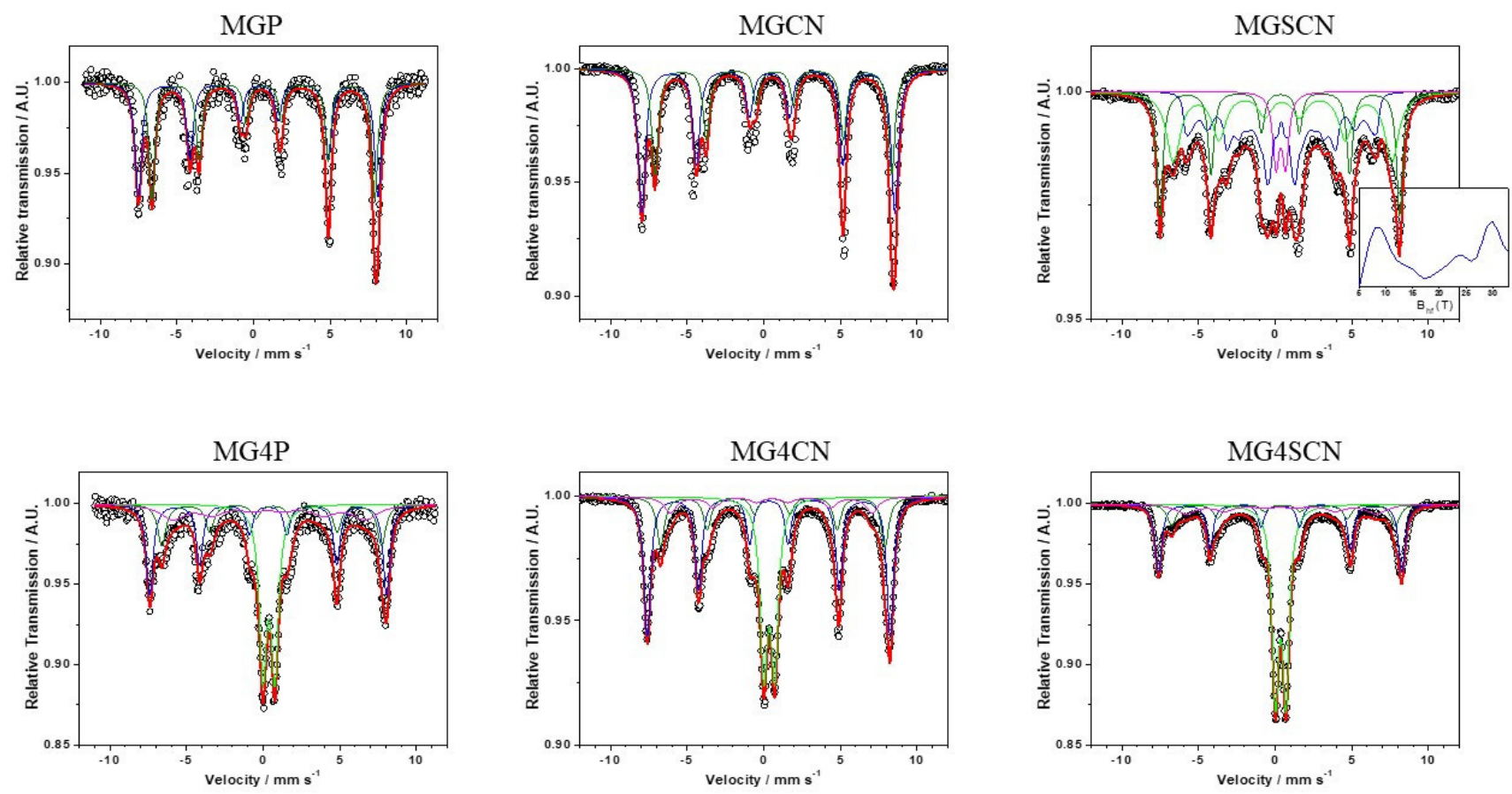

Figure 1. Mössbauer spectra of all magnetite samples.

Finally, we emphasize that the Mössbauer analysis-in spite of the recognized problems in the fit methodology-accomplished its role as a fingerprint technique, since it confirmed the presence of magnetite, goethite, and ferrihydrite phases. In conclusion, after correcting the fits and fixing the table of hyperfine parameters, the main conclusions of the paper are exactly the same as before.

Funding: This research received no external funding.

Conflicts of Interest: The authors declare no conflict of interest.

\section{References}

1. Nayak, P.K. Comment on Samulewski et al. Magnetite Synthesis in the Presence of Cyanide or Thiocyanate under Prebiotic Chemistry Conditions. Life 2020, 10, 34. Life 2021, 11, 1361. [CrossRef]

2. Samulewski, R.B.; Gonçalves, J.M.; Urbano, A.; da Costa, A.C.S.; Ivashita, F.F.; Paesano, A., Jr.; Zaia, D.A.M. Magnetite Synthesis in the Presence of Cyanide or Thiocyanate under Prebiotic Chemistry Conditions. Life 2020, 10, 34. [CrossRef] 